\title{
Proper activity, preference, and the meaning of life
}

\author{
Lucas 7. Mix ${ }^{\S}$
}

\begin{abstract}
Both popular and scientific definitions of life must account for the possibility of the suboptimal operation of some function. Identifying the function in question and the criteria for optimality will be necessary steps in crafting a definition that is both intuitive and rigorous. I lay out a rule of thumb - the proper activity criterion - and a three-part typology of binary, range, and preference for understanding definitions of life. The resolution of "optimal" function within a scientific framework presents the central challenge to creating a successful definition of life. A brief history of definitions of life and explanations of biological function is presented to demonstrate the value of the typology. After analyzing three controversial cases - viruses, mules, and stars - I present three possible options for resolution: vitalism, reductionism, and instrumentalism. Only by confronting the consequences of each can we come to consensus about what is necessary and desirable from a common definition.
\end{abstract}

\section{KEYWORDS \\ Astrobiology $\bullet$ Evolution $\bullet$ Life $\bullet$ Metabolism $\bullet$ Origin of Life}

\section{Introduction}

The primary challenge for generating a useful scientific definition of life comes from competing concepts of biological activity and our failure to make them explicit in our models. I set forth a three-part scheme for characterizing definitions of life, identifying a binary (presence or absence of some activity), a range (of operations for the activity), and a preference (for one end of the range). The three components together form a proper activity in biology (Table 1). To be clear, I am not proposing that proper activity be adopted as the best definition of life or even as a desirable definition for life. Instead, I am arguing that some notion of proper activity already exists within common scientific definitions. By making the implicit elements explicit, the notion can be analyzed to see whether it is useful and appropriate in the context of the biological sciences.

The preference component has proved problematic historically. Prior to 1600 , majority opinion was vitalist, holding that living things were ontologically different from the rest of the universe and governed by intrinsic, life-specific properties. Preference arose from internal sources, such as the soul. Over the next few centuries, modern science adopted mechanical explanations in place of vitalist explanations, replacing intrinsic properties with extrinsic universal forces acting on particles. A mechanical biology, however, was not embraced until the early 20th century, in part due to the apparent purposefulness of living things. I trace the

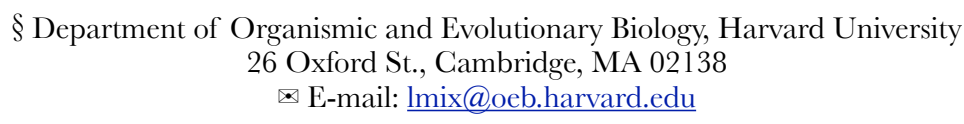

Received 12 April 2014; Revised 17 June 2014; Accepted 8 August 2014 


\begin{tabular}{|c|c|c|c|}
\hline $\begin{array}{l}\text { Proper Activity } \\
\text { Activity with Range and Preference }\end{array}$ & $\begin{array}{c}\text { Binary } \\
\text { Activity Present or Absent }\end{array}$ & $\begin{array}{c}\text { Range } \\
\text { Of Operation or Activity }\end{array}$ & $\begin{array}{c}\text { Preference } \\
\text { For One End of the Range ('Optimum') }\end{array}$ \\
\hline Metabolism & $\begin{array}{l}\text { maintaining or increasing } \\
\text { order locally at the } \\
\text { expense of increased entropy } \\
\text { in the environment }\end{array}$ & $\begin{array}{l}\text { (1) extent of disequilibrium } \\
\text { with environment } \\
\text { (2) length of time at disequilibrium }\end{array}$ & $\begin{array}{l}\text { (1) for greater disequilibrium } \\
\text { (e.g., order, complexity) } \\
\text { (2) for longer periods (persistence) }\end{array}$ \\
\hline Oparin & $\begin{array}{l}\text { storage of potential energy in a } \\
\text { suite of biochemical reactions }\end{array}$ & $\begin{array}{l}\text { quantity and density of } \\
\text { energy in the system }\end{array}$ & for higher quantity and density \\
\hline Schrödinger & localization of negative entropy & length of time to equilibrium & for longer delay \\
\hline Walker and Davies & data processing & processing speed & faster processing \\
\hline Nagel* $^{*}$ & self-regulation & $\begin{array}{l}\text { contribution to welfare } \\
\text { of organism or species }\end{array}$ & better contribution \\
\hline Bigelow and Pargetter* & survival & propensity for persistence ("fitness") & for higher propensity \\
\hline Evolution & imperfect self-replication & $\begin{array}{c}\text { (1) copy number } \\
\text { (2) copy number per generation } \\
\text { (3) copy speed } \\
\text { (4) copy fidelity }\end{array}$ & $\begin{array}{l}\text { (1) for more copies } \\
\text { (2) for greater allele frequency } \\
\text { in the population } \\
\text { (3) for faster replication } \\
\text { (4) for more accurate replication }\end{array}$ \\
\hline Muller & autocatalysis (of genes) & catalytic efficiency & for greater efficiency \\
\hline Foyce ('NASA') & capability for Darwinian evolution & fitness & for higher fitness \\
\hline Baross & capacity for adaptation & adaptation & for better fit with the environment \\
\hline Millikan* & $\begin{array}{l}\text { propagation of a type in tokens } \\
\text { ("reproduction") }\end{array}$ & token number and fidelity & $\begin{array}{l}\text { for more tokens functioning } \\
\text { according to type }\end{array}$ \\
\hline Neander* & replication of genes & $\begin{array}{l}\text { success in survival and } \\
\text { reproduction }\end{array}$ & for success \\
\hline
\end{tabular}

Table 1 - Proper Activity Analysis of Definitions of Life. Proper activity is broken down into binary, range, and preference for ten authors. For metabolic and evolutionary definitions, a number of possible ranges with attendant preferences are listed. "Efficiency" for the former and "fitness" for the latter are often invoked to indicate one or more of each without clearly stating which. (See Sections 5.2.2 and 6.1 for discussion.) *These authors are not explicitly defining life, but rather addressing function. Nonetheless, they reveal a concept of proper activity and, except Millikan, note a specifically biological proper activity.

history of metabolic and evolutionary definitions of life over the last century as they attempt to make proper activities consistent with mechanism. I also look at attempts in the late 20th century to explain the concept of function by appeals to a proper activity. With this groundwork in place, I address three problematic cases for definitions of life and use the proper activity framework to show why different definitions of life yield different answers for each problematic case and what that reveals about the continuing role of preference in our understanding of life. Finally, I look at vitalism and two non-vitalist approaches to preference that are currently competing within biology. Reductionism attempts to make preference and life into objective products of universal forces acting on matter. Instrumentalism claims preference, and consequently life, does 
not exist objectively, though it may be a useful way of talking about the universe. I list the issues that need to be resolved in order for one of the definitions or one of the concepts of preference to become standard within biology.

\section{Classifying Definitions of Life}

Scientific definitions of life can be characterized using a three-part typology that captures an important aspect of life, but may present philosophical difficulties. I call this aspect the "proper activity criterion": we use "life" to describe things that may be more or less effective at performing some activity we consider proper to them. This activity can be optimized, but only some minimal level of the activity is necessary. Thus, there are always three categories of activity operation: (i) active and functioning well, (ii) inactive or active and functioning poorly, and (iii) without activity. The poorly functioning category captures the essential character of terms like sick, sterile, and maladaptive. The most extreme version of this is death. Dead things were once living, while inanimate thing are simply not alive. Though "dead" and "inanimate" may be exchanged colloquially, they represent distinct concepts.

\subsection{The Binary: An Activity}

Evolutionary and metabolic definitions invoke a binary condition: the presence (or absence) of an activity. That activity need not be, in and of itself, unique to life, but rather any type of change through time. I am using activity in a broad, non-technical way. Replication, movement, catalysis, fractionation, and degradation are all activities associated with both living and non-living processes. Nuclear fusion, fission, and radiation are all activities not associated with life. It is unclear whether any activities are uniquely biological because the definition of "biological" remains unclear.

Metabolic definitions assign life an activity related to maintaining or increasing order locally at the expense of increased entropy in the environment. Since stars and crystals have this activity, most metabolic definitions add some further qualifier. Evolutionary definitions assign life an activity related to imperfect selfreplication. Since fire has this activity and many individual organisms do not; thus most evolutionary definitions add some further qualifier. In both cases, it is the nature of the qualifier that will cause difficulties. The concept of an activity alone does very little work. The need for qualifiers in both types of definition highlights the need for something more to differentiate life from non-life. Many authors have noted difficulties that arise from simple binary definitions of life (Bedau 2012b; Küppers 1990, 134; Mix 2009, 34). The answer, however, does not lie in aggregating together multiple activities. Dyson (1985) and Bedau (2010) have made such proposals. Other attempts to define life have included lists of activities, some or all of which must be present. As we will see, the difficult part of these definitions lies in the optimization of the activities. More activities simply make the definition more vague as each one usually requires its own modifiers.

Some confusion arises over whether the activity must be defined objectively. It might be essential (as Aristotle believed souls were), not essential but still objectively present (as Monod [1972, 12] saw "invariant reproduction"), or simply attributed (as Kant did with final causes to organisms). This question parallels the vitalist-reductionist-instrumentalist divide that we will encounter later (Section 5.2). I take it for granted that both maintenance and replication are intended as objective non-essential activities in most scientific definitions; however, the typology works regardless. The question of objectivity will be wrapped up in the approach to preference (Section 2.3). ${ }^{1}$

\subsection{The Range}

Maintenance and replication both exist within multiple spectra. If order is maintained, it may be kept closer to or farther from equilibrium with the environment and for shorter or longer periods of time. If objects are copied, they may be copied slower or faster, in smaller or larger batches, and more or less accurately. These spectra, like the activities they qualify, also exist for abiological activities. Radioisotopes, for example, decay with shorter and longer half-lives. Explicit definitions of life will need to address which range or ranges are relevant to the activity in question. 


\subsection{The Preference}

Work is done in our definitions by the preference component. Both metabolic and evolutionary definitions of life contain an appeal to optimum performance. More complex systems farther from equilibrium for longer periods constitute better maintenance. Persistence of a type for longer periods and in greater number constitutes better replication. The preference component is obscured by our use of the term "life" for both poorly and optimally performing individuals. Nonetheless, the definitions require that optimization be possible. They suggest that we will observe "dysfunctional" individuals, possessing the activity in question (binary), but at a lower level within the range than might be preferred.

I propose an informal diagnostic tool when assessing "life" and "biological" function. We think of an object as alive (or the product of life, including artifacts and dead bodies) when we can imagine it operating better or worse than it observably does. We think of a function as biological or artifactual when it can be optimized. An activity only becomes a "proper activity," useful as a definition of life, once we attach a concept of "better." Millikan (1984) and Neander (1995) have emphasized the importance of normativity in identifying "proper function," which they see as reducible to the effects of natural selection (but see Davies 2000 for an argument against). For them, preference reflects normativity relative to some activity of the organism. The preference in question here is for optimization of that activity. As McLaughlin (2001) cogently points out, these are not the same question. I deal with this in more detail below (Section 4).

\subsection{A Note on Artifacts}

There is a rich historical literature on artifacts, including their relationship to and derivation from living artificers. Artifacts clearly have a proper activity, which is derived from some organism. For my purposes, I include artifacts and all products of life within the definition of life. Some reference to historical treatments, however, will be helpful (Table 2).

Aristotle deals with this topic, curiously to modern ears, by claiming that nature is more purposive than art (Parts of Animals I.1; Johnson 2005). Artifacts have extrinsic accidental ends, while non-artifacts have intrinsic essential natures (Physics II.1; Johnson 2005). Proper activity (the nutritive soul) is invoked to differentiate life from artifacts. Nature (physis) is invoked to differentiate natural things like atoms from artifacts. Kant (Critique of Fudgment §64-65) makes a parallel but significantly different argument, defining artifacts by means of an external reason, alienating reason from nature, and associating final causes with intent. The organismic quality with which he characterizes "organisms" has to do with a super-empirical $a$ priori purposiveness ascribed to them by observers (Miller 2002). Proper activity is an imposition of reason onto artifacts and organisms. Monod (1972) claims that artifacts always channel the purpose or project of the organism that made them. He thinks proper activity objectively differentiates organisms and their products from everything else. McLaughlin (2001) claims that artifacts have (intended) purposes, traits of organisms have (unintentional) functions, and organisms have neither. He wants to separate the proper activities of artifacts from the proper activities of organisms based on intentionality.

All four authors, each with a radically different agenda, use the concept of artifact to amplify their own notion of proper activity: soul for Aristotle (Shields 2007, 2012), natural purpose for Kant, teleonomy for Monod, and the end of a "regress of means to ends" for McLaughlin. Common interpretations of the first three have been vitalist, instrumentalist, and reductionist, respectively. Note also that the four authors do not agree on what constitutes an artifact. Monod's artifacts can be produced by any living being, while Kant and McLaughlin's artifacts require a rational artificer.

I am unconvinced that one can objectively differentiate between organisms and their products. Technology, prostheses, hair, shells, symbioses, and waste products all serve some ends relative to both reproductive and metabolic definitions of life (Mix 2015). Thus I am willing, for the moment, to include artifacts (evidence of life) within my definitions of life. Further qualifiers may be added to separate the two categories, but I believe the question of preferences is more fundamental. 


\begin{tabular}{|c|c|c|c|}
\hline Representative & Living Things & Artifacts & Non-living, Non-art \\
\hline Aristotle & intrinsic nature (physis/psyche) & extrinsic ends & intrinsic nature (physis) \\
\hline Kant & (natural) purpose ascribed & (artificial) purpose ascribed & no purpose ascribed \\
\hline Monod & objective project (teleonomy) & objective project (teleonomy) & no project \\
\hline McLaughlin & unintended purpose & intended purpose & no purpose \\
\hline
\end{tabular}

Table 2 - Uses of Artifacts. See text for discussion.

\section{Historical Definitions of Life}

In the early 17 th century, the study of the physical world began what would become a radical shift in perspective. René Descartes and Pierre Gassendi proposed new models of the universe that have been labeled "mechanical." Descartes explicitly rejected the idea of intrinsic natures, choosing to explain everything in terms of particles and external laws (Garber 2002). Meanwhile, Gassendi rejected real qualities and substantial forms (scholastic categories for understanding Aristotle) in favor of colliding bodies in space (Osler 2010). A collection of similar philosophies took on the name "mechanical" to reflect their opposition to the Aristotelian concept of intrinsic properties, including teleology. Aristotelian natural philosophy relied upon natures (physis) as first principles. Aristotelian mechanics (at least as conceived by the scholastics) could be reduced to the action of universal laws on simple matter (Garber 2002). Boyle states it succinctly: "the phenomena of the world are physically produced by the mechanical properties of the parts of matter; and that they operate upon one another by mechanical laws" (quoted in Mayr 1982, 313). The motion of atoms under the influence of universal forces should be enough to explain everything.

This intentional shift to a mechanical perspective voided the explanatory work done by Aristotle's final causes in biology, reopening the question of how we are to understand living things. Descartes reduced animal souls to mechanisms with neither sensation nor agency, but kept human souls as non-extended extraphysical realities (Osler 2010). Kant, as we saw, privileged human attributions of purpose. Haeckel invoked progressive biological laws (Ruse 1996). Partly due to uncertainty over whether such explanations worked, the mechanical philosophy did not become the norm in biology until the late 19th and early 20th century. The shift occurs with Darwin, Mendel, and significantly, the Modern Synthesis (Ruse 1996). While scientific models have moved from explicitly mechanical to mathematical, the rejection of intrinsic natures remains. The question of exactly how we are to conceive of biological activities within this framework remains unresolved. Over the past century, scientific definitions of life have included two prominent schools of thought: metabolic and evolutionary (Chao 2000; Fleischaker 1990; Tirard et al. 2010; Walker and Davies 2013). ${ }^{2}$ The activities in question have remained the same, with extensive refinements in how they are characterized. The preferences that make them proper activities remain controversial.

\subsection{Metabolic Definitions}

Modern scientific definitions of life emerged in the 19th century with the recognition that physical particles and laws may be sufficient to explain life. It seemed clear by the mid-1800s that biological chemistry invoked the same elements and forces as abiological chemistry (Haeckel 1900; Bernal 1967). Explicitly naturalistic definitions of life were proposed by individuals like Thomas Henry Huxley, but it 
would take a synthesis of work by Charles Darwin, Gregor Mendel, and countless physiologists to pinpoint exact mechanisms.

"Metabolism" represents the complete suite of biochemical reactions leading to growth and life. A metabolic definition of life identifies the maintenance of that suite with "life." Oparin and Haldane were among the first to invoke chemical metabolism as the defining activity of living matter (Bernal 1967; Haldane 1929). Both thought energy was more abundant on early Earth. Spontaneous generation cannot happen now but it could then, and present life represents potential energy trapped in metabolic systems.

In the earliest expressly thermodynamic definition of life, Erwin Schrödinger (1992) characterized life as avoiding equilibrium by "feeding" on negative entropy: "living matter evades the decay to equilibrium...for a much longer period than we would expect [from] a piece of inanimate matter" (69). He admitted that the approach to equilibrium in abiological systems can take long periods, even centuries, making it somewhat difficult to specify an operational test of this delay. How long is long enough to constitute life? Maynard Smith (1986), among others, commented on this ambiguity. Nonetheless, Schrödinger provides a clear metabolic definition of life with a binary (localization of negative entropy), a range (length of time to equilibrium), and a preference (for longer delay). Subsequent definitions added significant details, but retain the central theme. Chyba and Macdonald (1995), invoking Küppers (1990), put it succinctly: "Metabolism is then no more than the turnover of free energy that makes it possible for a given system, compartmentalized or not, to avoid reverting to an equilibrium state of maximum entropy." In other words, metabolism has been redefined from a chemical system to an energetic one.

More recently, metabolism has been compared explicitly to computer technology to emphasize the work of proper activity. Dyson (1985), drawing on work by von Neumann, suggested an analogy to the hardware/ software dichotomy: a metabolic framework in which inheritable adaptive programs can run. Others appeal to biological programs and algorithms (Dennett 1995; Mayr 1961, 1982). Such thinking underlies much modern work on life as a metabolic network or information system (e.g., Alon 2007; Goldenfeld and Woese 2007). Maintenance is central, with a preference for optimized processing. Walker and Davies (2013) use explicit computer analogies. Within such a framework, the binary character of life is a processing unit, the range is processing speed, and the preference is for higher speeds and robustness in the system. Software returns us to the life as artifact theme, revealing that the most challenging aspect of our mechanical models has not gone away. Why are faster, more robust systems better?

\subsection{Evolutionary Definitions}

The story of modern evolutionary definitions starts with Hagedoorn (1911). He spoke of "autocatalysts" that not only replicate themselves, but also facilitate the replication of other molecules. ${ }^{3}$ Drawing on his ideas, Troland (1917; see also Muller 1966) proposed the "enzyme theory of life" where nucleic acids act in both capacities as autocatalysts and more broadly as enzymes. His model provided a concrete unit of inheritance by which natural selection can occur. Muller $(1926,1966)$ fleshed out Troland's ideas in a way that becomes recognizable as a modern definition of life. He specifically set out the gene as minimal protoplasm or minimal life. He also identified the chromosomes as a location for genes. Autocatalysis provided a proper activity for life with catalytic efficiency as the preference.

Subsequent evolutionary definitions have substantially refined the details of biochemical mechanisms by which these processes take place. The emphasis has shifted from chemical "autocatalysis" to organismic "replication" or "reproduction," but the outlines have remained the same for the last eighty years. The basic structure can be seen in Carl Sagan's Encyclopedia Britannica article on "Life" where he defines it as "a system capable of evolution by natural selection." Whereas earlier authors could think of a continuous process of autocatalysis going on inside the protoplasm, Sagan and later authors needed to account for the periodic, and occasionally dysfunctional, replication of whole organisms. It is at this point that mules and other sterile organisms become problematic, as well as individuals that might reproduce but have not. Hence the insertion of the word "capable." The new emphasis on organisms created difficulties for an operational definition (Chyba and MacDonald 1995; Fleischaker 1990; Luisi 1998). How do you determine a capability when there is no observed actuality? How do we understand the first replicator, capable of reproduction, but not the product of selection? 
Multiple evolutionary definitions exist, often with qualifications such as cellularity (to exclude viruses) or chemical composition (to exclude in silico replicators). One, perhaps the most popular, has been called the NASA definition based on its origins in the NASA Exobiology Program: "life is a self-sustained chemical system capable of undergoing Darwinian evolution" (Benner 2010; Joyce 1994). More recent attempts have emphasized the importance of inheritance, variation, and selection leading to adaptation (Bedau 2012a; Bedau and Packard 1992; Chao 2000; Maynard Smith 1986). "The canonical characteristics of life are an inherent capacity to adapt to changing environmental conditions and to increase in complexity by multiple mechanisms, but particularly by interactions with other living organisms (and, at least on Earth, also with viruses)" (Baross 2007, 218). This shifts the focus from a concrete activity - replication - to a potentiality or capacity for replication. The activity has become less concrete, while the preference remains undefined.

The term fitness has explanatory value in biology to the precise extent that it is coupled to adaptation. Fitness reflects better survival and reproduction. Though frequently expressed mathematically, it is not clear that a single underlying concept exists that captures multiple scales (levels of selection), multiple time frames (short term and long term fitness), and the persistence of types versus tokens. Biologists agree that fitness frames the preference, but they do not agree about what fitness means. As a measure of preferred suitability with an environment, the adaptive aspect of fitness remains normative. Terms such as "maladaptive" (phenotype) and "deleterious" (mutation) suggest that biologists do not view such changes neutrally. Failure to perform that function assigned by adaptation is viewed as a negative outcome (unless it comes with a new and more adaptive consequence).

\section{Functions in Biology}

Philosophy of biology contains an extensive literature on the meaning of function within biology. McLaughlin (2001) provides an excellent summary and commentary. While this question does not bear directly on the definition of life, it does have important implications for whether we view life through a vitalist, reductionist, or instrumentalist lens. My concept of proper activity closely mirrors several concepts proposed for the discussion of function in biology. In broad strokes, many philosophers have attempted to naturalize teleology and normative function either by reducing them to products of natural selection or instrumentalizing them relative to the capacity of some organism. As McLaughlin points out, problems arise for these chains of reasoning, both of which appear to be proper activities with a preference component.

\subsection{Etiological Theories}

In 1959, Hempel proposed "functional analysis" as an explication of how biological functions are explained objectively in terms of their contribution to the welfare of an individual or group in which they occur (Hempel 1994). He believed this elucidated the process of self-regulation in organisms, but could not provide a causal explanation. His successors were more ambitious and their positions have been called etiological because they attempt to explain the causes of functions, or teleological because they invoke a beneficiary (McLaughlin 2001). Larry Wright (1973, 1976), attempting to provide a mechanistic explanation of function, introduces the notion of feedback. He defines $Z$ as the function of $X$ when " $X$ is there because it does $Z$ " and " $Z$ is a consequence of $X$ 's being there." His beneficiary need not be an organism, but when it is, he invokes the survival and reproduction of that organism as the proper activity that justifies a proper function. Michael Ruse (1971) is both more explicit in his framework and more savvy with respect to evolutionary theory. He explicitly defines function in terms of adaptation, which provides relative reproductive success to the organism in which it occurs. Perhaps better than any other author, Ruse has managed to present a reductionist etiology of function that explains it via natural selection. I am unconvinced, however, that he has successfully eliminated the inductive problem of extrapolating from that which was adaptive in the past (or in another organism) to that which is adaptive in the present. Millikan (1984) addressed this problem with tokens and types. The normativity of a function in a token comes from its closeness in function to the type from which it was copied. Millikan calls this process of copying types "reproduction," intentionally coining a new usage of that word. Individual tokens function properly and are adaptive when they function according to type. The proliferation of the type forms the proper activity with a 
preference for more tokens. This analysis allows her to disentangle proximate and distal explanations for proper functions. (This was Mayr's [1992] chief complaint about Ruse's analysis.) It also allows her to speak about beneficiaries at many scales. Neander (1995) develops this reasoning further, explaining functions through an asymmetric series of "by-relations." Each proper function serves the proper activitycontribution to gene replication in biology - through a series of intermediates. For example, "the frog's optic fibres contributed to gene replication by helping to feed the frog by helping the frog catch flies" (125).

All of these etiological explanations of biological function rest on a notion, explicit or implicit, of replication as a proper activity with a preference for more copies; in other words, evolutionary definitions of life. With the exception of Wright (and possibly Hempel), they all accept some form of preference but, through a mechanistic reduction of it to natural selection, believe they have eliminated the problem of teleology.

\subsection{Dispositional Theories}

In 1961 Ernst Nagel argued that every effect could be viewed as a function when it contributes to the "characteristic activity of the system" (McLaughlin 2001). This is called the dispositional approach to functions because it focuses on what they do rather than how they came into existence. Nagel takes for granted that organisms have goals and in almost all of his examples they relate to self-regulation. But he avoids the question of what precisely these goals are (Nagel 1977a, b). Other dispositional approaches are less sanguine. Cummins (1975) attacks both Nagel and Hempel on just this question. If functions can be defended by an appeal to their containing system, then where do the functions of systems come from? If there is a proper level of system for reference (e.g., genes, individuals, societies,...), what is it? In the language of my analysis, if the functions of traits can be explained by appealing to the proper activity of organisms (or genes, or types,...), where do proper activities come from? More specifically, where does the preference that makes the activity "proper" come from? Cummins claims that functional ascriptions are always relative to some proposed analytical exercise. The capacity of the heart to beat contributes to the capacity of the body to make noise and also to the capacity of the vascular system to circulate blood. Like Kant, he sees functions as part of explanations, not part of nature. No proper activity is necessary, though some activities are interesting and amenable to functional analysis. Bigelow and Pargetter (1987) attempt to push this closer to objectivity with a theory of propensity. They invoke the likelihood that a creature will survive in its given habitat. The function of a trait reflects those features that increase the survival propensity of its host, presumably in proportion to their own likelihood of having an impact. Every effect that might improve survival, no matter how small the chance, is a function to some extent. Thus survival becomes the proper activity of organisms and higher fitness the preference. It remains unclear why the survival of nonorganisms does not also generate functions.

Dispositional explanations of biological function appeal to a range of proper activities, including selfregulation, replication, and survival. Thus, it can be hard to characterize them as appealing to one definition of life. They require different notions of preference, but uniformly interpret them in an instrumentalist manner.

\section{Future Definitions of Life}

There has been surprisingly little progress made in trying to define life scientifically. A framework was in place by the late 19th century and an ever increasing amount of detail has been added subsequently, but no consensus has been achieved. This may have more to do with the problematic nature of preferences within modern science than with any empirical problem, such as a lack of observations or a lack of theory.

The mechanical philosophy, including a rejection of intrinsic properties, has reigned in the physical sciences for nearly five centuries. It was not accepted in the biological sciences until the 20th century, however, perhaps due to strong associations between organisms and goal directed behavior or teleology. The rejection of teleology (Mitra 1986; Osler 2010, 144; Ruse 1996, 410-455) proves problematic for concepts of proper activity, once considered essential for a definition of life. In De Anima, Aristotle argued that the soul was not a dynamis, a capacity, but an energeion, a function in active use. Thus, the "entelechism" of Aristotle 
and centuries of biology was rejected. Modern science will allow for universal forces but not for localized purpose.

Over the last century, we have identified two important processes associated with life: evolution by natural selection and complex self-regulation. Each represents an activity associated with life that operates over a range of values. Those elements of the definitions are not problematic and have been steadily refined. Our definitions also require, however, a preference component. Attempts have been made to naturalize the preference component as well, but they have met with mixed success, sometimes because they were poorly characterized, other times because they represent deep philosophical disagreements.

\subsection{Borderline Cases}

The three-part characterization of definitions of life as a proper activity provides insights into why these disagreements exist and why they manifest in several popular borderline cases.

\subsubsection{Ambivalent Binary - Viruses}

There remains great disagreement about what the primary activity of life should be, or even if there is one. Viruses prove troubling because they possess the proper activity of adaptive replication without the proper activity of self-regulation. Viruses do not actively resist thermodynamic equilibrium with their environment, though they are copied and maintained by the metabolism of host cells. Nor do many consider them sufficiently complex to suffer sickness. Attribution of life may rest solidly and explicitly on which definition you use. It may also rest on our feeling that viral adaptation lacks the value or dignity of animal adaptation. Categorization of viroids, virusoids, plasmids, and gene transfer agents face similar problems.

\subsubsection{Confusion of Binary with Range - Mules}

Other intermediate cases suffer from the confusion of the binary and range components of a definition. Few biologists question that mules are alive and yet they are frequently cited as a case of an organism that cannot produce offspring. How can they then undergo Darwinian replication? The question here is not simply one of adaptation versus replication. Rather, we think the mule has a proper activity of organism level replication or reproduction, at which it fails. Mules have almost all the normal mechanisms for reproduction, but meiosis does not work properly, resulting in no viable gametes. The mule ceases to be an intermediate case once we recognize that its proper activity need not be carried out well in order for us to consider it alive.

Mules also highlight a composition problem regarding the definition of life. Just because meiosis fails, does not mean that mitosis does. Cellular replication occurs throughout the lifetime of a mule. The bias toward judging replication in terms of the organism rather than the cell is what leads us astray. There should be no question that mules represent living colonies of cells, even if they might not represent living individuals.

\subsubsection{Absent Preference - Stars}

Finally, stars highlight the importance of the preference component. They clearly meet many of the requirements for a classical metabolic definition of life. They drain the potential energy of a neighborhood in order to produce a complex, dynamic structure. They even produce energy in a form that organisms can feed on. They maintain an internal environment that allows a unique series of chemical reactions, which do not otherwise occur. Stars also resemble replicators, producing both energetic (shock wave) and material (nucleosynthetic) components contributing to the formation of other stars. They demonstrate a very weak form of inheritance, with more massive stars leading to the formation of heavier elements leading to more massive stars. 
In spite of having a clear activity and range related to the activities and ranges usually associated with life, stars are rarely presented as alive. This is because we do not associate preferences with them. Hotter and more massive stars are not considered better (or worse) than their siblings. Longer lasting stars are not lauded over shorter-lived stars. The closest we come to this kind of view is an instrumental preference for mid-range stars, which are more favorable for life (Mix 2009, 100-110).

I can think of many ways by which one could judge success for a star, but judgments of this kind are not made. Brown Dwarfs are occasionally called "failed stars," having insufficient mass to support fusion, but no opprobrium or disquiet attaches to such failure. No one says, "If only..." If such a lack is objective, we have yet to characterize it clearly. If it is merely instrumental taxonomy, then that will tell us something interesting about ourselves, if not about our stars.

\subsection{Moving Forward}

How can we move toward a consensus definition of life? The ambiguous concept of "better" contributes to the popularity of teleological explanations within (e.g., Pross 2005) and without (e.g., Nagel 2012) science and may not be compatible with methodological naturalism. I see this as the central obstacle in finding a definition of life that is satisfactory, both intuitively and scientifically. Machery (2012) argues that one cannot have it both ways: a definition of life must either be a scientific definition or a folk concept. On the contrary, I would argue that the purpose of a scientific definition must to be to construct a philosophically rigorous and empirically accountable definition that captures, to whatever extent possible, the folk concept. The general public may not think of $\mathrm{H}_{2} \mathrm{O}$ every time they think of water, but $\mathrm{H}_{2} \mathrm{O}$ accurately describes the common features of what they conceive. Scientists are not in the business of simply making things up. Folk counterexamples are posed to demonstrate that a given definition is insufficiently close to satisfy some standard of usefulness. The question of sufficiency is problematic, but hardly incomprehensible. No precise folk definition is necessary. Nonetheless, the scientific desire for clear communication and accurate representation of the natural world suggests that a better definition is called for. In the meantime, specific scientific programs addressing the boundaries of life in space and time require at least provisional definitions for life (Mix 2015). These definitions will need to account for preference in addition to binary and range.

Due to their invocation of optimum performance, proper activity definitions may not constitute good definitions from a scientific standpoint. How might optimum be defined objectively? The concepts are, however, implicit in both popular and current scientific definitions and should be addressed. To be clear, I am not arguing that the task cannot be accomplished. Rather, it can be accomplished and proposals have been made. One reason these have not been accepted is that they rely on uncommon premises. Broadly, those premises take one of three tacks (Table 3).

\subsubsection{Vitalism}

Preference within definitions of life could represent the effects of a life specific universal force. The 19th century witnessed a number of attempts to reconcile biological value with modern objectivism by introducing a "life force" in some way parallel to gravity and other physical forces. Just as gravity acts on anything with mass, so the vital force acts on anything alive.

If we subscribe to the mechanical philosophy, then vitalism will require "vitality" to be expressed in terms of an external force and a relevant particle or property of a particle. Proposals for a soul particle or elemental vitality have been proposed, from Lucretius' "soul seed" (De Rerum Natura, book 3) to Teilhard's "granular life" (1975: 92). Alternatively, one could propose vitality as a property of quarks or other fundamental particles. Coming from another angle, early modern biologists proposed a number of vital forces that push life forward (Ruse 2009). Notable examples include Henri Bergeson's "élan vital" and Herbert Spencer's "law of organic progress."

The vitalist position in science is amenable to empirical verification, specifically in the form of potential vital energy - distinct from potential energy in some other form-being stored in a system. Unless or until such data appears, vitalism cannot be considered a valid option. 


\begin{tabular}{|c|c|c|c|}
\hline Approach & Preference & Benefits & Costs \\
\hline Vitalism & $\begin{array}{l}\text { Comes from a life-specific } \\
\text { force or particle }\end{array}$ & $\begin{array}{l}\text { Historical, provides real } \\
\text { objective preferences }\end{array}$ & Does not match the data \\
\hline Reductionism & $\begin{array}{l}\text { Is reducible to interactions } \\
\text { of general physical } \\
\text { forces and particles }\end{array}$ & $\begin{array}{l}\text { Consistent with the data and } \\
\text { other branches of science, } \\
\text { parsimonious, provides concrete } \\
\text { programs of research }\end{array}$ & $\begin{array}{l}\text { Reduction of "fitness" } \\
\text { and "efficiency" require } \\
\text { currently unavailable } \\
\text { formalisms, risks alienating } \\
\text { folk and scientific definitions } \\
\text { of "preference" and "life" }\end{array}$ \\
\hline Instrumentalism & $\begin{array}{l}\text { Is useful in common discourse, but } \\
\text { is not objective }\end{array}$ & $\begin{array}{l}\text { Allows continued variety } \\
\text { and subjective usage } \\
\text { in productive science }\end{array}$ & $\begin{array}{c}\text { Provides no explanatory } \\
\text { value - proper activity } \\
\text { and life fail as } \\
\text { scientific categories }\end{array}$ \\
\hline
\end{tabular}

Table 3 - Three Approaches to Preference in Biology. See text for discussion.

\subsubsection{Reductionism}

Preference within definitions of life may represent the movement of previously identified universal physical forces. The most popular solution reduces biological function and biological value to a product of universal laws. Many scientists and philosophers have been explicit in their belief that biological explanations should be mechanistic (Ayala 1970) and/or naturalistic (Neander 1995). They want to naturalize biology.

Stars can be viewed as gravity powered engines that lower entropy locally. Could life be viewed as a preference-producing engine? Energy has been trapped in a complex chemical system as it runs down. Gravity powered stars produce photons as a waste product. Biospheres trap the energy of the photons in osmotic gradients and reducing power (NADPH, NADH, and ATP). Preference arises for whatever maintains the system, making stars and life equally eddies in the universal movement toward heat death.

This approach shows promise, but mostly shifts the probem from difficult metaphysical questions (What is life? Is life a natural kind?...) to difficult theoretical questions in biology (What constitutes an individual? What are the units of selection? How do short term and long term fitness relate?...) or difficult thermodynamic questions (How does one objectively bound an organism? What differentiates biological and abiological complexity?...). This analysis suggests that the way forward, should reductionism be the accepted approach, will require explicit regularization and mathematical reduction of the currently ambiguous concepts of biological fitness and efficiency. Mathematical models of feedback loops look promising. Muller (1926, 914) suggested that "autocatalysis" was a feedback process long before Wright (1976) offered it in philosophical treatments of function. For modern commentary, see Tsokolov (2010) and Bechtel (2011).

For both evolutionary and metabolic definitions, concrete models have been proposed, but they rest on premises that are not shared among all biologists. These premises are related to preference and the end of functional regresses. For evolutionary definitions, Alan Grafen $(1999,2014)$ is working on a mathematical formalism to capture fitness, but it takes individuals as the beneficiaries or "maximizing agents" following the trend set by R.A. Fisher and appearing frequently in etiological explanations of function. David Haig (2012, 2014) criticizes this approach, drawing on the concept of genes as the beneficiaries while invoking types and tokens. Birch (2014) has added questions about intrinsic versus extrinsic properties and what exactly it means to optimize the individual. That represents only one such controversy from the past year. For metabolic definitions, Sara Walker has tried to mathematically characterize top-down causation and information control in a way that would objectively reduce self-regulation (Walker and Davies 2013; Walker et al. 2012). She has also run into difficulties formalizing an objective metric. Once again there is a long history of formalisms, but none have been commonly accepted. 
It is not enough to claim that reduction is possible. One must provide a model by which the properties we wish to explain can be reduced without loss of explanatory power. Biologists in 1940s, 1970s, and 1990s all claimed that artificial life was just around the corner, but these predictions have not been borne out.

Can scientists and the general public accept this reduction? Are we willing to reduce the concept of biological preference to the products of natural selection (or metabolism)? If we do, are we then willing to reduce other forms of preference to biological preference or do we want to invoke some kind of human preference added on top? I'm not really comfortable with either option. Many philosophers appear convinced that "function" in psychology and sociology can be reduced to biological "function" and that biological "function" can be reduced to natural selection. Let us assume they are correct. Within the strict confines of evolutionary theory, I believe that Ernst Mayr's solution is generally accepted. Proximal teleonomy (proper activity or function) is a product of natural selection. Natural selection is not teleological (goal-driven) or even teleonomic (having a proper function) according to Mayr (1961), but it produces functional genetic programs. Mayr rejects cosmic teleology (1992), but I believe he would accept some form of teleonomy for the set of life on Earth. In discussing the definition of life, we must consider the possibility that all Earth life has a joint activity, range, and preference. If Darwin problematized the variety/species distinction, can we not also problematize the species/biosphere distinction and speak of a proper activity for the biosphere? Monod and Dennett both come close to making this suggestion. It seems the inevitable outcome of reductionism. All function and purpose, including our desire for good models, are simply the product of natural selection, at least from the scientific perspective,.

The reductionist approach makes sickness nothing more than a maladaptive condition or a more rapid dissipation of energy. Such a definition, while scientifically tractable, presents challenges for ethics and other branches of philosophy. We run the risk of separating the scientific and public discourses, as is the case for altruism, whose biological definition is now radically different from its popular and ethical definition.

Explicit reasoning about the distal end of the process would help resolve the question. We might constrain an evolutionary definition with a preference for increased overall biomass involved in a lineage or increased total number of copies of a gene set. Likewise, we could constrain a metabolic definition with a value for higher potential energy trapped in a system. These need not be the preferences we choose, but if they exist implicitly in the definition, we would benefit from explicitly discussing them. They have consequences beyond biology, including whether stars are classified as alive.

\subsubsection{Instrumentalism}

There could be no objective concept of preference. It may be that life is not a natural category, only a useful concept for describing the activity of organisms. Biologists frequently invoke helpful idealizations with terms that defy strict definition. The term "species" provides a classic example. While the biological species concept (species reflect populations that do or may interbreed) has been very useful in studying plants and animals, it admits of multiple counterexamples (e.g., ring species and hybrids) and simply does not apply to the vast majority of organisms, which do not reproduce sexually. As a more common example, "chair" remains a useful way of describing pieces of furniture, despite the fact that clear differentiae cannot be produced that will unfailing identify all chairs and non-chairs. Perhaps life is simply a useful way of describing a collection of objects and processes on Earth. McLaughlin (2001, 213) reflects that many biologists remain Kantian in their approach. Even if psychology and biology were reducible to biology and biology to natural selection, our concept of natural selection itself may not be objective.

A consciously instrumentalist approach would be transparent about our subjective use of preference in differentiating complex phenomena of biological interest (e.g., humans) from other complex phenomena (e.g., stars, flames, computer viruses). We could say that life represents systems in which we attribute preference regardless of whether the preference exists objectively. This would explain the fluid boundaries of biology as a discipline. It would prove extremely unsatisfying, however, when it comes to questions of the extent, origins, and purposes of life, which have attracted great interest. The term could no longer be invoked as an explanation for some observation or to compel some conclusion. 


\section{Conclusion}

Different people ask questions for different reasons. What work is a "definition of life" meant to do? Why do we care? What is it about life, however we define it, that impacts the way we live and the way we do science? Cleland (2012) has argued that no comprehensive definition of life is possible because the sample size is 1 . But we are interested in alien life because of some meaning life holds for us here on Earth. What we are looking for is not an abstract form of knowledge, but concrete entities, living elsewhere, that have similar meaning. Astrobiology at least demands an operational definition of life, so we can go looking for it, but also an understanding of the role of Earth life in human understanding, so we know what we are looking for.

A definition of life that will satisfy both a scientific and a general audience will need to capture the concepts of sickness and health in a way consistent with the mechanical philosophy. The two popular definitions of life, evolutionary and metabolic, attempt to solve the problem with an activity specific to living things. I have argued that this kind of activity is not enough. Such definitions also include some notion of preference attached to the activity, a preference not fully realized in sick or broken individuals. I propose the "proper activity criterion" as a diagnostic tool. If you can imagine a dysfunctional version of it, then it must be evidence of life (either a living thing or the product of a living thing). As a diagnostic, it is purely instrumental.

In order to advance the conversation, I also suggest adopting a three-part scheme for understanding definitions of life. This scheme includes a binary, a range, and a preference. In the examples covered here, the binary is an activity with a range of operation. Preference weights one end of the range with some significance lacking at the other end. Once all three elements are explicit, we can ask what type of value we are looking for and whether it is compatible with our philosophy. Vitalism, reductionism, and instrumentalism all provide rational approaches to the problem (although vitalism appears disproven by the evidence). By spelling out the consequences of these various definitions and approaches, I think we can find a common definition of life, or at least identify the underlying philosophical divides that make a common definition currently impossible.

Although I do not regard my own views as contributing directly to this central thesis, I briefly describe them here in the interest of transparency. With regard to definitions of life, I believe evolutionary definitions hold the most promise with imperfect replication as the activity. I have no trouble imagining a process occurring and producing "functions" at multiple levels from gene to population. I fear that there are no satisfactory answers to four, seemingly subjective questions. First, what do we mean by "imperfect"? Perfect replication does not lead to variation and subsequent selection. How close an entity needs to come to enter into natural selection and over what time scale requires clarification. Second, I do not understand how we might differentiate between self-replication and co-replication. Cellular phones represent a tremendously successful type with variation and selection. How do we differentiate between them, engineered sterile strains of corn, and the human "replicators" which engineer both? Third, I see increased biomass (excluding technology), increased mass devoted to a proper activity (including technology), and increased copy number as three different ends of "fitness" optimization. I cannot see how all three can be reconciled into one objective metric of fitness. Fourth, I do not see how to mathematically reduce short term and long term fitness into a single metric.

I suspect that sufficient rigor is impossible with regard to metabolic definitions of life, which strike me as even more subjective than their evolutionary cousins. To the best of my knowledge, all measures of complexity or information content that do not invoke intentional considerations must include stars and possibly planets within the category of life. Shannon entropy, for example, depends upon alphabet size. There is no objective way to determine whether a more concise alphabet could exist, making the value dependent upon the individuals attempting to code and decode a message.

With regard to reductionism and instrumentalism, I see the former as a hope for the future and the latter as a present necessity until the questions above have been reasonably answered. My hope for this paper is that it will encourage more concrete discussions around those issues whose resolution is necessary for reductionism to be a viable option. 


\section{Literature cited}

Alon, U. 2007. Simplicity in biology. Nature 446: 497-497.

Ayala, FJ. 1970. Teleological explanations in evolutionary biology. Philosophy of Science 37: 1-15.

Baross, J.A. 2007. Evolution, a defining feature of life. In: Planets and Life: The Emerging Science of Astrobiology. Ed. by W.T. Sullivan and J.A. Baross. Cambridge: Cambridge University Press.

Bechtel, W. 2011. Mechanism and biological explanation. Philosophy of Science 78: 533-537.

Bedau, M.A. 2010. An account of minimal chemical life. Astrobiology 10: 1011-1020.

Bedau, M.A. 2012a. A functional account of degrees of minimal chemical life. Synthese 185: 73-88.

Bedau, M.A. 2012b. Introduction to philosophical problems about life. Synthese 185: 1-3.

Bedau, M.A. and N.H. Packard. 1992. Measurement of evolutionary activity, teleology, and life. In Artificial Life II. Ed. by C. Langton, C. Taylor, D. Farmer, and S. Rasmussen. Santa Fe Institute Studies in the Sciences of Complexity, Vol. X. Redwood City, CA: Addison-Wesley.

Bernal, J.D. 1967. The Origin of Life. Cleveland: World Publishing Company.

Benner, S.A. 2010. Defining life. Astrobiology 10: 1021-1030.

Bigelow, J. and R. Pargetter. 1987. Functions. Journal of Philosophy 84: 181-196.

Birch, J. 2014. Has Grafen formalized Darwin? Biology \& Philosophy 29: 175-180.

Chao, L. 2000. The meaning of life. BioScience 50: 245.

Chyba, C.F. and G.D. McDonald. 1995. The origin of life in the solar system: current issues. Annual Review of Earth and Planetary Sciences 23: 215-249.

Cleland, G.E. 2012. Life without definitions. Synthese 185: 125-144.

Cleland, G.E and C.F. Chyba. 2007. Does 'life' have a definition? In: Planets and Life: The Emerging Science of Astrobiology. Ed. by W.T. Sullivan and J.A. Baross. Cambridge: Cambridge University Press.

Cummins, R. 1975. Functional analysis. Journal of Philosophy 72: 741-765.

Davies, P.S. 2000. Malfunctions. Biology \& Philosophy 15: 19-38.

Dennett, D.C. 1995. Darwin's Dangerous Idea: Evolution and the Meanings of Life. New York: Simon \& Schuster.

Dyson, F.J. 1985. Origins of Life. Cambridge: Cambridge University Press.

Fleischaker, G.R. 1990. Origins of life: an operational definition. Origins of Life and Evolution of Biospheres 20: 127-137.

Garber, D. 2002. Descartes, mechanics, and the mechanical philosophy. Midwest Studies in Philosophy 26: 185-204.

Goldenfeld, N. and C. Woese. 2007. Biology's next revolution. Nature 445: 369-369.

Grafen, A. 1999. Formal Darwinism, the individual-as-maximizing-agent analogy and bet-hedging. Proceedings of the Royal Society B: Biological Sciences 266: 799-803.

Grafen. A. 2014. The formal Darwinism project in outline. Biology \& Philosophy 29: 155-174.

Haeckel, E. 1900. The Riddle of the Universe. New York: Harper.

Haig, D. 2012. The strategic gene. Biology \& Philosophy 27: 461-479.

Haig, D. 2014. Genetic dissent and individual compromise. Biology \& Philosophy 29: 233-239.

Haldane, J.B.S. 1929. The origin of life. The Rationalist Annual 3: 3-10.

Hempel, C.G. 1994 [1959]. The logic of functional analysis. In: Readings in the Philosophy of Social Science. Ed. by M. Martin and L.C. McIntyre. Cambridge, MA: MIT Press.

Hagedoorn, A.L. 1911. Autokatalytical Substance: The Determinants for the Inheritable Characters, A Biochemical Theory of Inheritance and Evolution. Leipzig: Verlag von Wilhelm.

Johnson, M.R. 2005. Aristotle on Teleology. Oxford: Clarendon.

Joyce, G.F. 1994. Foreword. In: Origins of Life: The Central Concepts. Ed. by D.W. Deamer and G.R. Fleischaker. Boston, MA: Jones and Bartlett.

Kitcher, P. 1993. Function and design. Midwest Studies in Philosophy 18: 379-397.

Koshland, D.E. 2002. The seven pillars of life. Science 295: 2215-2216.

Küppers, B-O. 1990. Information and the Origin of Life. Cambridge, MA: MIT Press. 
Luisi, P.L. 1998. About various definitions of life. Origins of Life and Evolution of the Biosphere 28: 613622.

Machery, E. 2012. Why I stopped worrying about the definition of life...and why you should as well. Synthese 185: 145-164.

Maynard-Smith, J. 1986. The Problems of Biology. Oxford: Oxford University Press.

Mayr, E. 1961. Cause and effect in biology. Science 134: 1501-1506.

Mayr, E. 1982. The Growth of Biological Thought: Diversity, Evolution, and Inheritance. Cambridge, MA: Harvard University Press.

Mayr, E. 1992. The idea of teleology. Journal of the History of Ideas 53: 117-135.

McLaughlin, P. 2001. What Functions Explain: Functional Explanation and Self-Reproducing Systems. New York: Cambridge University Press.

Miller, E. 2002. The Vegetative Soul: From Philosophy of Nature to Subjectivity in the Feminine. Albany, NY: State University of New York Press.

Millikan, R.G. 1984. Language, Thought, and Other Biological Categories: New Foundations for Realism. Cambridge, MA: MIT Press.

Mitra, S.B. 1886. Physiological selection and the origin of species. Nature 34: 385-386.

Mix, L.J. 2009. Life in Space: Astrobiology for Everyone. Cambridge, MA: Harvard University Press.

Mix, L.J. 2015. Defending definitions of life. Astrobiology 15: 15-19.

Monod, J. 1972. Chance and Necessity; an Essay on the Natural Philosophy of Modern Biology. New York: Vintage Books.

Muller, H.J. 1926. The gene as the basis of life. Proceedings of the International Congress of Plant Sciences 1: 897-921.

Muller, H.J. 1929. The method of evolution. Scientific Monthly 29: 481-505.

Muller, H.J. 1966. The gene material as the initiator and the organizing basis of life. American Naturalist 100: 493-517.

Nagel, E. 1977a. Functional explanations in biology. Journal of Philosophy 74: 280-301.

Nagel, E. 1977b. Goal-directed processes in biology. Journal of Philosophy 74: 261-279.

Nagel, T. 2012. Mind and Cosmos: Why the Materialist Neo-Darwinian Conception of Nature is Almost Certainly False. New York: Oxford University Press.

Neander, K. 1995. Misrepresenting and malfunctioning. Philosophical Studies 79: 109-141.

Osler, M.J. 2010. Reconfiguring the World: Nature, God, and Human Understanding from the Middle Ages to Early Modern Europe. Baltimore, MD: Johns Hopkins University Press.

Pross, A. 2005. On the chemical nature and origin of teleonomy. Origins of Life and Evolution of Biospheres 35: 383-394.

Ruse, M. 1971. Functional statements in biology. Philosophy of Science 38: 87-95.

Ruse, M. 1996. Monad to Man: The Concept of Progress in Evolutionary Biology. Cambridge, MA: Harvard University Press.

Schrödinger, E. 1992. What Is Life? The Physical Aspect of the Living Cell; with, Mind and Matter \& Autobiographical Sketches. Cambridge: Cambridge University Press.

Shields, C. 2007. Aristotle. New York: Routledge.

Shields, C. 2012. The dialectic of life. Synthese 185: 103-124.

Sober, E. 1992. Learning from functionalism - prospects for strong artificial life. In: Artificial Life II. Ed. by

C Langton, C Taylor, D Farmer and S Rasmussen. Santa Fe Institute Studies in the Sciences of Complexity, Vol. X. Redwood City, CA: Addison-Wesley.

Sober, E. 1993. Philosophy of Biology. New York: Oxford University Press.

Teilhard de Chardin, P. 1975. The Phenomenon of Man. New York: Harper \& Row.

Tirard, S., M. Morange, and A. Lazcano. 2010. The definition of life: a brief history of an elusive scientific endeavor. Astrobiology 10: 1003-1009.

Troland, L.T. 1917. Biological enigmas and enzyme action. American Naturalist 51: 321-350.

Varela, F. and H. Maturana. 1972. Mechanism and biological explanation. Philosophy of Science 39: 378382. 
Tsokolov, S. 2010. A theory of circular organization and negative feedback: defining life in a cybernetic context. Astrobiology 10: 1031-1042.

Walker, S.I. and P.C.W. Davies. 2013. The algorithmic origins of life. Journal of the Royal Society Interface 10: 20120869.

Walker, S.I., L. Cisneros, and P.G.W. Davies. 2012. Evolutionary transitions and top-down causation. Proceedings of Artificial Life XIII: 283-290.

Wright, L. 1973. Functions. Philosophical Review 82: 139-168.

Wright, L. 1976. Teleological Explanations: An Etiological Analysis of Goals and Functions. Berkeley, CA: University of California Press.

\section{Notes}

1. For more on attributed, natural, and essential activities as they relate to definitions of life, see Varela and Maturana (1972), Sober (1993), Kitcher (1993), Bedau (2010), and Shields (2012).

2. I am not making the general claim that all scientific definitions of life correspond to "sickness" definitions, only these two (i.e., metabolic and evolutionary). Systematic lists of all such definitions often include biochemical and syndrome definitions as well (e.g., Cleveland and Chyba 2007, 120). Biochemical definitions may lack sensitivity and selectivity, and therefore have not been popular as operational definitions. Abiotic complex organic molecules have been found in meteorites and alien life may not be organic. Syndrome definitions provide lists of life symptoms rather than an essential character (e.g, Koshland 2002). They are not ideal definitions and the symptoms always include replication and metabolism. Thus, evolutionary and metabolic definitions provide a good starting place for analysis.

3. In general, I have avoided careful distinctions between the terms reproduction and replication. Attempts have been made to separate them on several grounds. Dyson (1985) suggests that replication produces identical copies while reproduction does not. Common usage does not follow this pattern; DNA replication is not perfect, nor would DNA reproduction sound right. Nor does the increase in entropy allow for perfect copies without infinite energy. All forms of copying introduce errors at some level. Millikan (1984) suggests reproduction be re-tasked specifically for copies of types. Others restrict reproduction to organisms and replication to everything else. Both of these short-circuit the discussion at hand.

\section{AGKNOWLEDGMENTS}

Thanks to John Armstrong, Carl Bergstrom, Sarah Kocher, Jen Kotler, Shanti Rao, Michael New, David Lamberth, and two anonymous reviewers for comments. Thanks to David Haig for office space. This publication was made possible through the support of a grant from the John Templeton Foundation. The opinions expressed in this publication are those of the author and do not necessarily reflect the views of the John Templeton Foundation.

Copyright (C) 2014 Author(s).

This is an open-access article distributed under the terms of the Creative Commons Attribution-NonCommercial-NoDerivs license, which permits anyone to download, copy, distribute, or display the full text without asking for permission, provided that the creator(s) are given full credit, no derivative works are created, and the work is not used for commercial purposes.

ISSN 1949-0739 